\title{
Occurrence of Saxitoxin in a Green Turban Shell*1
}

\author{
Takeshi YASUMOTO*2 and Yuichi KoTAKI*2 \\ (Received August 2, 1976)
}

\begin{abstract}
From the viscera of a green turban shell Turbo marmorata collected at an Okinawan coral reef, a water soluble toxin resembling saxitoxin was obtained. The chromatographic behavior of the toxin on columns of ion exchange resin, silicic acid, and Sephadex LH-20 coincided well with that of saxitoxin. Thin-layer chromatography with two solvents also could not differentiate between the two toxins. In qualitative chemical tests, the green turban toxin was positive to Jaffe and Weber reagents, as was saxitoxin. As regards the biological activity, the two toxins gave practically the same dose-death time curves when tested on mice. From all these results it was concluded that the green turban toxin is identical with saxitoxin. This may be the first report of the occurrence of saxitoxin in a mollusc associated with coral reefs.
\end{abstract}

Our previous survey on toxins contained in molluscs associated with coral reefs revealed presence of a strong toxin in the water soluble fraction of a green turban shell Turbo marmorata. ${ }^{11}$ In a subsequent preliminary test this toxin of the green turban (GTT) was found to be a basic compound of small molecule, stable in acidic media but unstable in alkaline media, and to show an acute paralytic action to mice. These properties well reminded us of saxitoxin (SXT). Accordingly our subsequent effort was concentrated on comparison of the toxin with SXT. The standard purification procedures for SXT were effectively applicable to purification of GTT. The behaviors of GTT during chromatography with ion-exchange resin, silicic acid, Sephadex LH-20, and thin-layers were well comparable with those of SXT. Qualitative spot tests and dose-death time relationship for GTT and SXT also supported their identity. More details of the evidences will be given in the present paper.

\section{Materials and Methods}

Materials Specimens of the green turban were collected at a coral reef of Ishigaki Island, Okinawa Prefecture, in August 1974 and 1975. For the extraction of the toxin $2 \mathrm{~kg}$ of the viscera was used.

Extraction of the toxin From the minced viscera the toxin was extraced three times with three volumes of boiling methanol. The combined methanol extracts were concentrated and the concentrate was extracted in a separatory funnel first with diethyl ether and then with 1-butanol. Subsequently the aqueous layer was diluted with 4 volumes of etha-

*1 Toxicity Study on Marine Snails-VII.

*2 Laboratory of Food Science, Faculty of Agriculture, Tohoku University, Sendai (安元 健 - 小滝裕 一：東北大学祳学部食糔化学科). 
nol and the precipitates were removed by filtration. The supernatant was evaporated to dryness and the residue was used as the crude toxin for further experiments.

Preliminary test on the nature of GTT Following preliminary tests were carried out to obtain information on the molecular size, stability, and electric charge of the toxin.

First, the toxin was subjected to gel-filtration through Sephadex G-10 column and the elution volume was compared with that of choline.

Secondly, the toxin was dissolved in solutions of $1 \mathrm{~N}$ hydrochloric acid, $1 \mathrm{~N}$ acetic acid, and $1 \mathrm{~N}$ ammonium hydroxide and the solutions were heated in a boiling water bath for $2 \mathrm{hr}$. After evaporation of each solution the residue was tested for toxicity.

Thirdly, an aliquot of toxin was loaded on a column of Dowex 50W-X8 $\left(\mathrm{H}^{+}\right.$form, 200-400 mesh). The column was washed first with water and then with hydrochloric acid of different concentrations ranging from 1 to $6 \mathrm{~N}$.

Purification Standard purification method for SXT was applied to GTT. First, GTT was treated on columns of Amberlite CG-50 in $\mathrm{Na}^{+}$form according to the method of Schantz et al. ${ }^{2)}$ For silicic acid column chromatography the method of GHAZAROSSIAN et al. ${ }^{3)}$ was employed. Gel permiation chromatography was carried out on a column $(3.0 \times 50 \mathrm{~cm})$ of Sephadex LH-20 using $50 \%$ ethanol as the solvent.

Thin-layer chromatography Thin-layer chromatographic comparison of GTT with SXT was performed on silica gel G (Merck) layers with the following two solvents: A, 1-butanol-acetic acid-water $(2: 1: 1)$ and $\mathrm{B}, t$-butanol-acetic acid-water $(2: 1: 1)$. Detection of the spots in the chromatograms was made by either Weber reagent or $50 \%$ sulfuric acid solution. The hydrogen peroxide-fluorescence reaction described by BUCKLEY et al. ${ }^{4}$ ) and bioassay of the toxin after elution from the adsorbent were also carried out.

Qualitative test GTT was tested by the following coloring reagents: Jaffe, ${ }^{\left({ }^{6}\right)}$ Weber, ${ }^{6}$ ) hydrogen peroxide, ${ }^{4)}$ ninhydrin, and Dragendorff ${ }^{5}$ reagents.

Dose-death time relationship The dose-death time relationships for both the GTT and SXT were determined in a manner described by Konosu et al. ${ }^{7}$

Distribution of GTT in the tissues Ten specimens of the green turban were dissected into the muscle, gill, viscera, and ingested materials. The same tissues were pooled and subjected to quantitative toxicity assay which is currently in use for SXT. ${ }^{8)}$

\section{Results}

In the preliminary tests on Sephadex G-10 column, GTT was found to have a void volume very close to that of choline, indicating the smallness of the molecule. It was stable in acidic media but unstable in alkaline medium, was retained by the cation exchange resin and was eluted from the column only with relatively high concentration of hydrochloric acid (from 3 to $6 \mathrm{~N}$ ). These results together with its acute paralytic action 
on mice were well suggestive of SXT.

Resemblances between GTT and SXT became more evident when comparison was made by chromatographic procedures which originally had been deviced for purification of SXT. ${ }^{2)}$ From the Amberlite CG-50 (Na ${ }^{+}$form) column, GTT was recovered in $0.5 \mathrm{~N}$ acetic acid fraction. On silicic acid column the toxin was eluted with $96 \%$ ethanol, similar to SXT. Upon gel-filtration through Sephadex LH-20 column, the toxin appeared in fraction Nos. 51-54. Reference SXT also appeared in exactly the same fractions. Through all the chromatographic procedures, the recovery of the toxin was always higher than $85 \%$. The minimum lethal dose of the toxin purified by these chromatographic techniques was estimated to be less than $0.1 \mathrm{mg} / \mathrm{kg}$ when tested by intraperitoneal injection into mice. It reacted to the Jaffe and Weber reagents but not to the Dragendorff and ninhydrin reagents. It gave a fluorescent spot when treated with hydrogen peroxide. Tests on thin-layers also could not differentiate GTT from SXT by any solvent or detecting reagent employed. On mice assay, the band corresponding to the Rf value of SXT was toxic but no other area of the chromatogram was toxic.

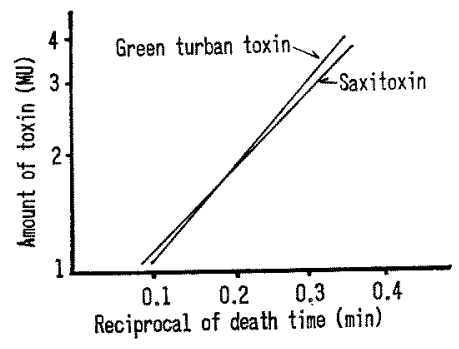

Fig. 1. Dose-death time relationships for the green turban toxin and saxitoxin.
Table 1. Distribution of toxin in the tissue of Turbo marmorata

\begin{tabular}{lc}
\hline \multicolumn{1}{c}{ Tissue } & Toxicity $(\mathrm{MU} / \mathrm{g})$ \\
\hline Viscera* & 6.7 \\
Gut contents & $2 \sim 4$ \\
Gills & $2 \sim 4$ \\
Muscle & $<2$ \\
\hline
\end{tabular}

* Viscera except gut contents.

The dose-death time relationship obtained on both GTT and SXT is shown in Fig.1, in which the reciprocal of death time is plotted against the logarithm of dosage. It may be seen that the two lines are practically the same.

All the results so far obtained unequivocally indicate that GTT is indistinguishable from SXT in chromatographic, chemical, and biological properties.

The distribution of the toxin in the tissues is shown in Table 1. Toxicity was detectable in the gill, viscera, and ingested materials but not in the muscle.

\section{Discussion}

In view of the data obtained in the present study, it may be reasonably concluded that the toxin found in the green turban is identical with or closely related to saxitoxin. Occurrence of this toxin in a herbivorous snail mollusc may be worthy to note although 
some carnivorous snails are already known to accumulate SXT by feeding toxic bivalves. ${ }^{8}$ Obviously the green turban too obtain the toxin from the food as indicated by the toxicity of the ingested materials. Therefore, it seems quite probable that more number of animals associated with coral reefs acquire SXT through the food chain. A good example may be the report by HASHIMOTO et al. ${ }^{9}$ in which presence of SXT in three species of xanthid crab was demonstrated. On the other hand the feeding habit of both the xanthid crabs and green turban raises a new question as regards the origin of the toxin. So far, occurrence of SXT in marine orgnisms has been always connected with the dinoflagellate of Gonyaulax spp., except the case of the xanthid crabs. However, such blooms of SXT-producing planktons are never known in Okinawa. In addition neither the xanthid crabs nor the green turban is a plankton feeder. Instead they feed on the algae and detritus on the coral beds. On the contrary to our expectation, the filter feeders on the coral reefs such as tridacnas do not contain SXT. ${ }^{1)}$ These facts suggest a possibility that some benthic organism, other than Gonyaulax, produces SXT. Further study would be necessary to find out the source of the toxin. A future study is also planned on the distribution of SXT in other organisms associated with coral reefs.

From the food hygienic point of view, it is important to point out that some specimens of the viscera tested in the present study showed a toxicity higher than 4 mouse unit per gram materials which is the maximum level allowed for SXT in food. ${ }^{8)}$ Although the viscera of the snail molluscs are not considered as foodstuffs in Okinawa, caution should be paid to the use of the green turban.

Though recent studies on Gonyaulax tamarensis, coexistence of toxins other than SXT has become apparent. ${ }^{10}$ These toxins, it is reported, are discriminable from SXT by both column chromatography and thin-layer chromatography. In our present study, however, presence of such toxins was not recognized.

\section{Acknowledgements}

The authors wish to express their sincere thanks to Messers. S. KINJYO and K. OsHIRO for their help in collecting the specimens. Thanks are also due to Prof. Y. Hashimoto and Dr. T. NoGUCH, University of Tokyo, for the generous gift of saxitoxin and to Prof. T. KANEDA of this laboratory for his encouragement during this study. A part of the study was supported by a grant from the Ministry of Education.

\section{References}

1) K. Kanno, Y. KotakI, and T. Yasumoto: This Bull., 42, 1395-1398 (1976).

2) E. J. Schantz, J. D. Mold, D. W. Stanger, J. Shavel, F. J. Riel, J. P. Bowden, J. M. Lynch, R. S. Wyler, B. RifGel, and H. Sommer: J. Am. Chem. Soc., 79, 5230-5235 (1957). 
3) V. E. Ghazarossian, E. J. Schantz, H. K. Schnoes, and F. M. Strong: Biochem. Biophys. Res. Commun., 59, 1219-1225 (1974).

4) L. J. Buckley, M. IKawa, and J. J. Sasner, Jr.: J. Agric. Food Chem., 24, 107-111 (1976).

5) E. StaHL: Thin-layer chromatography, 2nd. ed., Springer-Verlag, New York, 1969, pp. 854-908.

6) C. J. Weber: J. Biol. Chem., 78, 465-473 (1928).

7) S. Konosu, A. Inoue, T. Noguchi, and Y. Hashimoto: Toxicon, 6, 113-117 (1968).

8) A. Prakash, J. C. Medof, A. D. Tennant: Bull. Fish. Res. Bd. Canada, 17, 1-87 (1971).

9) Y. Hashimoto, S. Konosu, A. Inoue, T. Saisho, and S. MiyaKe: This Bull., 35, 83-87 (1969).

10) Y. Shtmizu, M. Alam, Y. Oshima, and W. E. Fallon: Biochem. Biophys. Res. Commun., 66, 731-737 (1975). 